\title{
PENGARUH KEGIATAN POSYANDU AYAH TERHADAP PENCAPAIAN SKDN DI POSYANDU DESA PULO GEBANG DAN POSYANDU DESA GUBUS BANARAN WILAYAH KERJA PUSKESMAS TEMBELANG KABUPATEN JOMBANG
}

\author{
Influence of Posyandu Ayah Activities On Achievement of SDKN In Posyandu Pulo Gebang \\ Village and Posyandu Banaran Village in Working Area Of Puskesmas Tembelang, Jombang \\ District
}

\author{
Mudhawaroh ${ }^{1}$, Septi Fitrah $N^{2}$, Niken Grah Prihartanti ${ }^{3}$ \\ ${ }^{123}$ STIKES PEMKAB JOMBANG \\ aryajati13@gmail.com
}

\begin{abstract}
Riwayat Artikel
Diajukan: Februari 2020

Diterima: Maret 2020

Penulis Korespondensi:

- Mudhawaroh

- aryajati13@gmail.com
\end{abstract}

\section{Kata Kunci:}

Posyandu Ayah, Pencapaian SKDN, Balita

\section{ABSTRAK}

Pendahuluan : Posyandu merupakan salah satu bentuk Upaya Kesehatan Bersumber Daya Masyarakat (UKBM) yang dikelola dan diselenggarakan dari, oleh, untuk, dan bersama masyarakat dalam penyelenggaraan pembangunan kesehatan, guna memberdayakan masyarakat dan memberikan kemudahan kepada masyarakat dalam memperoleh pelayanan kesehatan dasar untuk mempercepat penurunan angka kematian ibu dan bayi. Selain itu, posyandu merupakan bentuk partisipasi masyarakat yang sungguh membawa arti yang sangat besar bagi kesehatan dan kesejahteraan masyarakat.Keberhasilan posyandu dapat terlihat dari pencapaian SKDN. Tujuan dalam penelitian ini adalah Menganalisis pengaruh kegiatan posyandu ayah terhadap pencapaian SKDN.

Metode : Penelitian ini menggunakan metode observasional analitik dengan rancangan penelitian cross sectional,. Populasi dalam penelitian ini adalah Populasi dalam penelitian ini adalah semua Partisipan dalam kegiatan Posyandu, Teknik sampling yang digunakan dalam penelitian ini adalah simple random sampling. Sampel berjumlah 50 orang pada kedua kelompok. Analisis data dilakukan dengan univariat dan bivariat, pengujian statistik menggunakan uji Uji Mann Whitney dengan tingkat kepercayaan 95\% $(\alpha=0,05)$

Hasil : Hampir seluruhnya balita di kelompok posyandu ayah mengalami peningkatan pada bulan juli - September sejumlah 44 (88\%) dan pada kelompok control sebagian besar naik dengan jumlah $34(68 \%)$. Partisipasi responden (D/ S) dengan nilai > 80\% terdapat pada kelompok kasus, sedangkan peningkatan beratbadan dalam 3 bulan terakhir dengan nilai $>80 \%$ terdapat pada kelompok kasus. $\mathrm{p}<$ $\alpha$, dimana nilai $0,047<0$, 05 sehingga dapat disimpulkan ada pengaruh Kegiatan posyandu ayah terhadap pencapaian SKDN.

Pembahasan : Dengan adanya posyandu ayah maupun posyandu balita mampu meningkatkan kesadaran masyarakat tentang pentingya kesehatan balita, dengan berpartisipasi juga akan meningkatkan berat badan anak. Indikator yang paling sederhana di posyandu adalah "Anak sehat bertambah umur bertambah berat badan" Dan ini juga adalah yang menjadi ikon dari keberadaan posyandu (pos penimbangan), sekaligus juga berlaku sebagai output untuk semua kegiatan di posyandu.

\section{Kata Kunci : Posyandu Ayah, Pencapaian SKDN, Balita}

\section{ABSTRACT}

Introduction: Posyandu is one form of Community-Based Health Efforts (UKBM) which is managed and organized from, by, for, and together with the community in organizing health development, in order to empower the community and provide facilities to the public in 
obtaining basic health services to accelerate the decline in numbers maternal and infant deaths. In addition, posyandu is a form of community participation that truly carries enormous significance for the health and welfare of the community. Posyandu success can be seen from the achievement of SKDN. The purpose of this research is to analyze the influence of father's Posyandu activities on the achievement of SKDN.

Method: This study used an observational analytic method with a cross sectional study design. The population in this study is the population in this study are all participants in Posyandu activities, the sampling technique used in this study is simple random sampling. A sample of 50 people in both groups. Data analysis was performed by univariate and bivariate, statistical testing using the Mann Whitney Test with a confidence level of $95 \%(\alpha=0.05)$

Results: Almost all toddlers in the father's posyandu group experienced an increase in July - September by $44(88 \%)$ and in the control group the majority rose by $34(68 \%)$. Respondent participation (D / S) with a value $>80 \%$ was found in the case group, while the increase in body weight in the last 3 months with a value $>80 \%$ was found in the case group. $\mathrm{p}<\alpha$, where the value is $0.047<0,05$ so that it can be concluded that there is an influence of the father's Posyandu activity on the achievement of SKDN.

Discussion: With the presence of the father's posyandu and toddlers' posyandu, it can increase public awareness about the importance of toddler health, by participating will also increase the child's weight. The simplest indicator in a posyandu is "Healthy children get older, gain weight" And this is also an icon of the existence of a posyandu (weighing post), as well as acting as an output for all activities at the posyandu.

\section{Keywords: Father's Posyandu, SKDN Achievement, Toddler}

\section{PENDAHULUAN}

Tujuan pembangunan kesehatan menuju Indonesia Sehat 2025 adalah meningkatnya kesadaran, kemauan, dan kemampuan hidup sehat bagi setiap orang agar peningkatan derajat kesehatan masyarakat yang setinggi -tingginya dapat terwujud, melalui terciptanya masyarakat, bangsa dan negara Indonesia yang ditandai oleh penduduknya yang hidup dengan perilaku dan dalam lingkungan sehat, memiliki kemampuan untuk menjangkau pelayanan kesehatan yang bermutu. Sasaran pembangunan kesehatan yang akan dicapai pada tahun 2025 adalah meningkatnya derajat kesehatan yang ditunjukkan oleh indikator dampak khususnya pada bayi dan balita antara lain menurunnya angka kematian bayi dari 32,3 per 1.000 kelahiran hidup pada tahun 2005 menjadi 15,5 per 1.000 kelahiran hidup pada tahun 2025 serta menurunnya prevalensi gizi kurang pada balita dari $26 \%$ pada tahun 2005 menjadi $9,5 \%$ pada tahun 2025. Maka salah satu pembangunan kesehatan yang akan ditempuh sampai tahun 2025 adalah Semua Rukun warga/ lingkungan telah memiliki minimal satu posyandu aktif yang melaksanakan kegiatan minimum sebulan sekali (Depkes RI, 2009).

Posyandu merupakan salah satu bentuk Upaya Kesehatan Bersumber Daya Masyarakat (UKBM) yang dikelola dan diselenggarakan dari, oleh, untuk, dan bersama masyarakat dalam

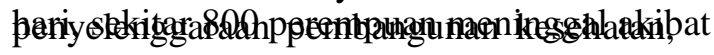
guna memberdayakan masyarakat dan memberikan kemudahan kepada masyarakat dalam memperoleh pelayanan kesehatan dasar untuk mempercepat penurunan angka kematian ibu dan bayi. Selain itu, posyandu merupakan bentuk partisipasi masyarakat yang sungguh membawa arti yang sangat besar bagi kesehatan dan kesejahteraan masyarakat.Keberhasilan posyandu dapat terlihat dari pencapaian SKDN, dimana SKDN adalah status gizi balita yang digambarkan dalam suatu balok SKDN, dimana balok tersebut memuat tentang sasaran balita di suatu wilayah (S), balita yang memiliki KMS (K), balita yang ditimbang berat badannya (D), balita yang ditimbang dan naik berat badannya $(\mathrm{N})$, SKDN tersebut diperoleh dari hasil posyandu yang dimuat di KMS dan digunakan untuk memantau pertumbuhan balita (Depkes RI, 2003).

Balita baru yang diperiksa kesehatannya sekaligus dicek tumbuh kembangnya oleh Petugas Puskesmas/Puskesmas Pembantu Polindes di dalam maupun diluar Institusi Kesehatan seperti di Posyandu. Balita yang naik berat badannya adalah Balita yang pada waktu ditimbang di fasilitas kesehatan atau posyandu mengalami kenaikan berat badan sesuai pedoman apabila dibandingkan dengan hasil penimbangan sebelumnya. 
Posyandu balita identik dengan tugas kaum perempuan atau ibu mengantar anaknya, tetapi pada posyandu ayah peduli peran serta juga kepedulian para ayah mengantar ke posyandu, serta adanya kader laki -laki yang turut memberikan pelayanan, sehingga kesehatan juga tumbuh kembang anak akan semakin baik. Sehingga deran adanya peran dan keterlibatan ayah dalam kegiatan posyandu dapat diharapkan meningkatkan derajat kesehatan balita,dan dapat terciptanya keluarga yang sadar akan kesehatan, dengan cara rutin membawa balitanya datang ke posyandu. Sehingga dapat terciptanya pencapaian SKDN sesuai dengan capaian nasional.

Tujuan penelitian ini adalah Menganalisis pengaruh kegiatan posyandu ayah terhadap pencapaian SKDN di Posyandu Desa Pulo Gebang dan Posyandu Desa Gubus Banaran Wilayah Kerja Puskesmas Jati Wates Kabupaten Jombang.

\section{METODE}

Metode penelitian merupakan salah satu tahapan penelitian yang harus diperhatikan dengan sebaik - baiknya agar penelitian dapat dilaksanakan dengan serasi untuk mencapai tujuan penelitian (Suyanto, 2009). Metode yang digunakan dalam proses penelitian ini meliputi : desain penelitian, waktu dan tempat, kerangka kerja, sampling disain, identifikasi variabel, definisi operasional, pengumpulan data, analisa data, etika penelitian.

Desain penelitian yang digunakan dalam metode penelitian ini adalah Ditinjau dari rancang bangunnya, desain penelitian ini menggunakan rancangan cross sectional, dimana pengamatan variable bebas (independent) dan variable terikat (dependent) dilakukan dalam satu waktu secara bersamaan sehingga dapat diketahui Pengaruh kegiatan posyandu ayah terhadap pencapaian SKDN. Populasi dalam penelitian ini adalah Semua Partisipan dalam kegiatan Posyandu Ayah di Posyandu ayah sebanyak 119 responden dan di Posyandu balita sebanyak 119 responden. Teknik sampling, yang digunakan dalam penelitian ini adalah probability sampling dengan jenis Simple
Random Sampling dengan jumlah jumlah reponsden 50 balita.

Penelitian ini dilaksanakan di di Posyandu Ayah di Desa Gabus Banaran dan Posyandu Balita Desa Pulo Gebang Wilayah Kerja Puskesmas Jati Wates Kabupaten Jombang dilaksanakan pada bulan Juli - September tahun 2018.

\section{HASIL PENELITIAN}

\section{Data Umum}

Data umum menggambarkan tentang karakteristik responden meliputi:

1) Usia 2) Jenis Kelamin

a. Distribusi responden berdasarkan usia

Tabel 1 Tabel distribusi

Responden Berdasarkan Usia di Posyandu

Desa Pulo Gebang dan Posyandu Desa

Gabus Banaran Wilayah Kerja Puskesmas Jati Wates Kabupaten Jombang Tahun 2018

\begin{tabular}{ccccc}
\hline Usia & \multicolumn{2}{c}{ Kasus } & \multicolumn{2}{c}{ Kontrol } \\
& n & \% & n & \% \\
\hline 0-23 Bulan & 28 & 56 & 23 & 46 \\
:4-60 Bulan 22 & 44 & 27 & 54 \\
Jumlah & 50 & 100 & 50 & 100 \\
\hline
\end{tabular}

\section{Sumber : Data Primer Tahun 2018}

Berdasarkan table 1 dapat dilihat bahwa menurut usia menunjukkan bahwa pada kelompok kasus sebagian besar balita berusia $0-23$ bulan sebanyak 28 balita (56\%) dan pada kelompok control sebagian besar balita berusia 24-60 bulan sebanyak 27 balita (54\%).

b. Distribusi responden berdasarkan Jenis Kelamin

Tabel 2 distribusi Responden Berdasarkan Jenis Kelamin di Posyandu Desa Pulo Gebang dan Posyandu Desa Gabus Banaran Wilayah Kerja Puskesmas Jati Wates Kabupaten Jombang Tahun 2018

\begin{tabular}{ccccc}
\hline $\begin{array}{c}\text { Jenis } \\
\text { kelamin }\end{array}$ & \multicolumn{2}{c}{ Kasus } & \multicolumn{2}{c}{ Kontrol } \\
\hline Laki laki & 30 & 6 & 28 & 5 \\
Perempuan & 20 & 4 & 22 & 4 \\
Jumlah & 50 & 1 & 50 & 1 \\
\hline
\end{tabular}

Sumber : Data Primer Tahun 2018 
Berdasarkan table 4.2 dapat dilihat bahwa pada kelompok kasus berdasarkan jenis kelamin balita menunjukkan bahwa sebagian besar balita berjenis kelamin laki laki sebanyak 30 balita (60\%) dan pada kelompok control sebagian besar berjenis kelamin laki laki sebanyak 28 balita $(56 \%)$.

\section{Data Khusus}

Pada data ini akan dibahas: a) Berat Badan Balita Bulan Juli -September 2018 b) pencapaian SKDN c) Pengaruh Kegiatan posyandu Ayah Terhadap Pencapaian SKDN

a. Karakteristik responden berdasarkan Berat Badan Balita Bulan Juli -September 2011

Tabel 3 Tabel distribusi Responden Berdasarkan Berat Badan Balita Bulan Juli September 2018 di Posyandu Desa Pulo Gebang dan Posyandu Desa Gabus Banaran Wilayah Kerja Puskesmas Jati Wates Kabupaten Jombang Tahun 2018

\begin{tabular}{cllcc}
\hline Berat Badan & Kasus & \multicolumn{3}{c}{ Kontrol } \\
& n & \% & n & \% \\
\hline Naik & 4 & 8 & 3 & 6
\end{tabular}

$\begin{array}{ccccc}\text { Turun/ tetap } & 6 & 1 & 1 & 3 \\ \text { Jumlah } & 5 & 1 & 5 & 1\end{array}$

Sumber : Data Primer Tahun 2018

Berdasarkan table 3 dapat dilihat bahwa pada kelompok kasus berat badan balita hampir seluruhnya mengalami peningkatan pada bulan juli - September sejumlah 44 (88\%) dan pada kelompok control sebagian besar naik dengan jumlah $34(68 \%)$.

\section{b. Karakteristik pencapaian SKDN}

Tabel 4. distribusi Responden Berdasarkan Pencapaian SKDN di Posyandu Desa Pulo Gebang dan Posyandu Desa Gabus Banaran Wilayah Kerja Puskesmas Jati Wates Kabupaten Jombang Tahun 2018

\begin{tabular}{lcc}
\hline $\begin{array}{c}\text { Pencapaian } \\
\text { SKDN }\end{array}$ & $\begin{array}{c}\text { Kelompok } \\
\text { kasus }\end{array}$ & $\begin{array}{c}\text { Kelompok } \\
\text { kontrol }\end{array}$ \\
\hline D/ S & $83 \%$ & $79 \%$ \\
N/ D & $88 \%$ & $68 \%$ \\
\hline
\end{tabular}

Sumber : Data Primer Tahun 2018
Berdasarkan table 4.4 dapat dilihat bahwa Partisipasi responden (D/ S) dengan nilai $>80 \%$ terdapat pada kelompok kasus, sedangkan peningkatan beratbadan dalam 3 bulan terakhir dengan nilai > $80 \%$ terdapat pada kelompok kasus.

c. Pengaruh Kegiatan posyandu Ayah Terhadap Pencapaian SKDN

Tabel 5. Tabel Pengaruh Kegiatan posyandu Ayah Terhadap Pencapaian SKDN di Posyandu Desa Pulo Gebang dan Posyandu Desa Gabus Banaran Wilayah Kerja Puskesmas Jati Wates Kabupaten Jombang Tahun 2018

\begin{tabular}{cc}
\hline Karakteristik & Nilai p \\
\hline Posyandu Ayah - & 0,047 \\
Posyandu Balita &
\end{tabular}

\section{Sumber : Data SPSS Tahun 2018}

Berdasarkan table 4.5 didapatkan hasil bahwa $\mathrm{p}<\alpha$, dimana nilai $0,047<0$, 05 sehingga dapat disimpulkan ada pengaruh Kegiatan posyandu ayah terhadap pencapaian SKDN.

\section{PEMBAHASAN}

\section{Berat Badan Balita Bulan Juli - September 2018 pada Posyandu Ayah dan Posyandu Balita \\ Berdasarkan table 4.3 dapat dilihat} bahwa pada kelompok kasus berat badan balita hampir seluruhnya mengalami peningkatan pada bulan juli - September sejumlah 44 (88\%) dan pada kelompok control sebagian besar naik dengan jumlah 34 (68\%). Terdapat perbedaan antara peningkatan berat badan balita pada kelompok posyandu ayah dan posyandu balita.

Posyandu merupakan salah satu bentuk Upaya Kesehatan Bersumber Daya Masyarakat (UKBM) yang dikelola dan diselenggarakan dari, oleh, untuk, dan bersama masyarakat dalam penyelenggaraan pembangunan kesehatan, guna memberdayakan masyarakat dan memberikan kemudahan kepada masyarakat dalam memperoleh pelayanan kesehatan dasar untuk mempercepat penurunan angka kematian ibu dan bayi. Selain itu, posyandu merupakan bentuk partisipasi masyarakat yang sungguh 
membawa arti yang sangat besar bagi kesehatan dan kesejahteraan masyarakat (Pedoman Umum Pengelolaan Posyandu, Depkes RI,2006). Pada posyandu ayah, lebih menekankan keterlibatan ayah dalam kegiatan posyandu, baik sebagai kader maupun sebagai ayah dalam mendampingi balita untuk datang ke posyandu. Adanya perbedaan peningkatan berat badan tentunya tidak hanya disebabkan karena kedatangan balita ke posyandu, faktor lain yang dapat mempengaruhi kenaikan berat badan balita antara lain asupan makanan yang diberikan kepada anak, sikap dan perilaku ibu/orang tua kepada anak, dimungkinkan bisa mempengaruhi berat badan balita. Setelah ditemukan adanya kenaikan berat badan, berat badan turun ataupun berat badan naik, sebaiknya ada tindak lanjut dari petugas kesehatan dengan cara melakukan penyuluhan tentang gizi seimbang, memberikan dukungan dan motivasi pada orang tua agar berat badan anak dapat naik, memberikan tambahan makanan pada anak, dan melakukan rujukan apabila ada masalah dalam pertumbuhan dan perkembangan anak yang tidak sesuai.

\section{Pencapaian SKDN}

Berdasarkan table 4.4 dapat dilihat bahwa Partisipasi responden (D/ S) dengan nilai $>80 \%$ terdapat pada kelompok kasus, sedangkan peningkatan beratbadan dalam 3 bulan terakhir dengan nilai > $80 \%$ terdapat padakelompok kasus. SKDN adalah status gizi balita yang digambarkan dalam suatu balok SKDN, dimana balok tersebut memuat tentang sasaran balita di suatu wilayah (S), balita yang memiliki KMS (K), balita yang ditimbang berat badannya (D), balita yang ditimbang dan naik berat badannya $(\mathrm{N})$, SKDN tersebut diperoleh dari hasil posyandu yang dimuat di KMS dan digunakan untuk memantau pertumbuhan balita (Depkes RI, 2003). Terdapat beberapa indikator dalam penilaian SKDN, Indikator $\mathrm{D} / \mathrm{S}$ (D/S adalah indikator yang menggambarkan tingkat partisipasi masyarakat dalam kegiatan di posyandu), Indikator N/D adalah memberikan gambaran tingkat keberhasilan program dalam kegiatan UPGK di posyandu. Indikator ini lebih spesifik dibanding dengan indikator lainnya sehingga dapat digunakan sebagai gambaran dasar gizi balita

$\begin{array}{ccc}\text { Berdasarkan } & \text { hasil } & \text { penelitian } \\ \text { didapatkan bahwa pada } & \text { kelompok }\end{array}$ posyandu ayah nilai $\mathrm{D} / \mathrm{S}>80 \%$ dan pada kelompok posyandu balita $<80 \%$ pada penilaian ini yang dinilai adalah partisipasi masysrakat dalam kegiatan posyandu. Partisipasi adalah keterlibatan masyarakat masyrakat secara sukarela dalam perubahan yang ditentukan sendiri oleh masyarakat.Selain itu partisipasi juga diartikan sebagai keterlibatan masyarakat dalam upaya pembangunan lingkungan, kehidupan, dan diri mereka sendiri (Mikkelsen 2003). Adi (2007) menjelaskan lebih jauh mengenai partisipasi bahawa masyarakat terlibat dalam program pemberdayaan mulai dari proses pengidentifikasian masalah dan potensi yang ada di dalam masyarakat, pemilihan dan pengambilan keputusan tentang alternative solusi untuk menangani masalah, pelaksanaan upaya mengatasi masalah dan keterlibatan masyarakat dalam proses mengevaluasi perubahan yang terjadi. Dimana partisipasi sendiri dapat dipengaruhi oleh Jenis kelamin, usia. Padakegiatan posyandu ayah partisipasi masyarakat lebih banyak dimungkinkan karena ayah ingin lebih berperan dalam mengantarkan balita keposyandu demi mengetahui pertumbuhan dan perkembangan anak, dikarenakan kegiatan ini biasa dilakukan pada hari libur. Sedangkan pada posyandu balita biasa dilaksanakan pada hari efektif, dimana banyak ibu yang bekerja sehingga partisipasi masyarakat tidak lebih dari $80 \%$.

\section{Pengaruh Kegiatan posyandu Ayah Terhadap Pencapaian SKDN}

Berdasarkan table 5 didapatkan hasil bahwa $\mathrm{p}<\alpha$, dimana nilai $0,047<0$, 05 sehingga dapat disimpulkan ada pengaruh Kegiatan posyandu ayah terhadap pencapaian SKDN.

Kegiatan Posyandu merupakan kegiatan rutin yang diselenggarakan sertiap 1bulan sekali, dimana dalam setiap kali pertemuan terdapat beberapa pelayanan antara lain: Pelayanan yang diselenggarakan untuk ibu hamil 
mencakup penimbangan berat badan dan pemberian tablet besi yang dilakukan oleh kader kesehatan, Penyuluhan KB, ASI dan gizi, ibu nifas, perawatan kebersihan jalan lahir, pemberian vitamin A dan tablet besi, perawatan payudara, senan ibu nifas. Pelayanan Posyandu untuk balita harus dilaksanakan secara menyenangkan dan memacu kreativitas tumbuh kembang anak.Jika ruang pelayanan memadai, pada waktu menunggu giliran pelayanan, anak balita sebaiknya tidak digendong, melainkandilepas bermain sesame balita dengan pengawasan orang tua dibawah bimbingan kader. Adapun jenis pelayanan yang diselenggarakan posyandu untuk balita mencakup : penimbangan berat badan, penentuan status pertumbuhan, penyuluhan dan jika ada tenaga kesehatan puskesmas, dilakukan pemeriksaan kesehatan, imunisasi dan deteksi dini tumbuh kembang. Apabila ditemukan kelainan, segera dirujuk ke puskesmas. Sehingga dengan kegiatan posyandu ayah maupun posyandu balita mampu untuk mendeteksi adanya masalah pertumbuhan dan perkembangan anak.

Tentunya dalam suatu program pastinya terdapat target pencapaian, salah satunya yaitu pencapaian SKDN. Dari hasil analisis didapatkan hasil ada pengaruh posyandu ayah terhadap pencapaian SKDN, yang artinya dengan adanya posyandu ayah maupun posyandu balita mampu meningkatkan kesadaran masyarakat tentang pentingya kesehatan balita, dengan berpartisipasi juga akan meningkatkan berat badan anak. Indikator yang paling sederhana di posyandu adalah ANAK SEHAT BERTAMBAH UMUR BERTAMBAH BERAT BADAN. Dan ini juga adalah yang menjadi ikon dari keberadaan posyandu (pos penimbangan), sekaligus juga berlaku sebagai output untuk semua kegiatan di posyandu.

\section{KESIMPULAN}

1. Hampir seluruhnya balita di kelompok posyandu ayah mengalami peningkatan pada bulan juli - September sejumlah 44 (88\%) dan pada kelompok control sebagian besar naik dengan jumlah 34 $(68 \%)$.

2. Partisipasi responden (D/ S) dengan nilai $>80 \%$ terdapat pada kelompok kasus, sedangkan peningkatan beratbadan dalam 3 bulan terakhir dengan nilai > $80 \%$ terdapat pada kelompok kasus.

3. $\mathrm{p}<\alpha$, dimana nilai $0,047<0,05$ sehingga dapat disimpulkan ada pengaruh Kegiatan posyandu ayah terhadap pencapaian SKDN.

\section{DAFTAR PUSTAKA}

Bapenas. 2008. Internet. “

Assessment Kapasitas Lokal".

http://www.issdp.ampl.or.id/v2. Diakses

29 Februari 2018).

Depkes RI. 2005. Pedoman Pelaksana: Program Pelayanan Kesehatan

Puskesmas.

Depkes RI. 2006. Profil Kesehatan Provinsi Sul-Sel.

Dinkes Takalar. 2010. Profil Puskesmas Towata

Gemari. 2005. "Maksimalkan TP PKK untuk kelola Posyandu”. Majalah Keluarga Mandiri.

Kesmas. 2007. "Jurnal kesehatan Masyarakat Nasional". Fakultas Kesehatan Masyarakat Universitas Indonesia.

Naim, Umar. 2008." POSYANDU:Upaya Kesehatan Berbasis Masyarakat”. Penerbit Kareso. Yogyakarta.

Nanik S. 2007. Internet."Kota Bogor Siap Menyongsong Kelurahan Siaga 2008".http://kotabogor.go.id/index, diakses I Maret 2010.

Nursalam.2003. "Konsep dan Penerapan Metodologipenelitian Ilmu Keperawatan".Salemba Medika. Jakarta.

Pohan, Imbalo. 2007. "Jaminan Mutu Layanan Kesehatan: Dasar-Dasar Pengertian dan Penerapan”. EGC. Jakarta.

Sciortino, Rosalina. 2000. "Mепијu Kesehatan Madani". Penerbit Pustaka Pelajar. Yogyakarta. 
Setiadi, (2007).Konsep dan Penulisan Riset Keperawatan, Yogyakarta: Graha Ilmu.

STIKES Tanawali Persada Takalar. (2009). Buku Panduan Penelitian, Takalar: Stikes Tanawali Persada Takalar.

Suara karya. 2006. Internet "Desa Siaga Berdayakan Potensi Lokal Menuju Desa Sehat".http://www.suarakarya online com/news.htmi, Diakses 1 Maret 2018.

Sulkan Y. 2000. "Kamus Bahasa Indonesia: Praktis Populer dan Kosakata Baru”. Penerbit Mekar. Surabaya.

Supari, Fadilah. 2006. Internet. "Melalui Desa Siaga, Rakyat Sehat".http://www.promosikesehatan.com/ news.html, Diakses 29 Februari 2018.

Surya. 2007. Internet. "Desa Siaga Dikembangkan di Jawa Timur dengan Mengaktifkan

Kader".http://www.surya.co.id/web.

Diakses 29 Februari 2018.

Uli, Mailt. 2005.Internet. "Kader Kesehatan Siap Memasyarakatkan Hidup Bersih dan Sehat Kepada Masyarakat".htts://www.unilever.co.id/our comoan /beritaandmedia, diakses 3 maret 2018.

Unicef. 2000. "Buku Kader Usaha Perbaikan Gizi Keluarga”. UPGK. Jakarta. Widiastuti, Agung, I Gusti. 2006. Internet. "Pemanfaatan Pelayanan Posyandu di Kota Denpasar".http://www.lrckmpk.ugm.ac.id/id/up-pdf. Diakses 29 Febuari 2018.

Widodowati, Retno Lestari. 2004. "Warta Kesehatan Masyarakat". Pelatihan Kader Posyandu Desa Sukabumi.

Zulkifli. 2003. Internet. "Posyandu dan KaderKesehatan".

http://www.library.usu.ac.id/modules.php.

Diakses $\quad 1$ maret 2018 . 
Jurnal Ilmiah Kebidanan (Scientific Journal of Midwifery), Vol 6, No. 1 Tahun 2020 